\title{
BMJ Open Gender-based approach on the social impact and mental health in Spain during COVID-19 lockdown: a cross- sectional study
}

\author{
Constanza Jacques-Aviñó (D) , ${ }^{1}$ Tomàs López-Jiménez, ${ }^{1}$ \\ Laura Medina-Perucha (10) ," Jeroen de Bont, ${ }^{1,2,3,4}$ \\ Alessandra Queiroga Gonçalves, ${ }^{5,6}$ Talita Duarte-Salles (D) , ${ }^{1}$ \\ Anna Berenguera (1) 1,7
}

To cite: Jacques-Aviñó C, López-Jiménez T, MedinaPerucha L, et al. Gender-based approach on the social impact and mental health in Spain during COVID-19 lockdown: a cross-sectional study. BMJ Open 2020;10:e044617. doi:10.1136/ bmjopen-2020-044617

- Prepublication history for this paper is available online. To view these files, please visit the journal online (http://dx.doi. org/10.1136/bmjopen-2020044617).

Received 08 September 2020 Revised 05 0ctober 2020 Accepted 23 October 2020

\section{Deck for updates}

(c) Author(s) (or their employer(s)) 2020. Re-use permitted under CC BY-NC. No commercial re-use. See rights and permissions. Published by BMJ.

For numbered affiliations see end of article.

\section{Correspondence to} Dr Constanza Jacques-Aviñó; cjacques18@yahoo.es; cjacques@idiapjgol.info

\section{ABSTRACT}

Objective Lockdown has impacts on people's living conditions and mental health. The study aims to assess the relations between social impact and mental health among adults living in Spain during COVID-19 lockdown measures, taking a gender-based approach into account. Design, setting and participants We conducted a cross-sectional study among adults living in Spain during the lockdown of COVID-19 with an online survey from 8 April to 28 May 2020. The main variable was mental health measured by Generalized Anxiety Disorder Scale for anxiety and the Patient Health Questionnaire for depression. Sex-stratified multivariate ordinal logistic regression models were constructed to assess the association between social impact variables, anxiety and depression.

Results A total of 7053 people completed this survey. A total of $31.2 \%$ of women and $17.7 \%$ of men reported anxiety. Depression levels were reported in $28.5 \%$ of women and $16.7 \%$ of men. A higher proportion of anxiety and depression levels was found in the younger population (18-35 years), especially in women. Poorer mental health was mainly related to fear of COVID-19 infection, with higher anxiety levels especially in women (adjusted ordinal OR (aOR): $4.23,95 \% \mathrm{Cl} 3.68$ to 4.87 ) and worsened economy with higher levels of depression in women (aOR: $1.51,95 \% \mathrm{Cl} 1.24$ to 1.84), and perceived inadequate housing to cope with lockdown was especially associated with anxiety in men (aOR: $2.53,95 \% \mathrm{Cl} 1.93$ to 3.44 ). Conclusion The social impact of the lockdown is related to gender, age and socioeconomic conditions. Women and young people had worse mental health outcomes during lockdown. It is urgent to establish strategies for public health emergencies that include mental health and its determinants, taking a gender-based approach into account, in order to reduce health inequities.

\section{INTRODUCTION}

Strict lockdown measures have been implemented since 15 March to 20 June 2020 to control the COVID-19 outbreak in Spain. The implementation of these public health

\section{Strengths and limitations of this study}

- This study assesses lockdown measures from a gender perspective.

- The results show important changes in the mental health of Spanish residents compared with previous cross-sectional studies.

- The scores for the individual mental health tests are consistent with the health survey from other countries in order to establish comparisons.

- The survey was available online and was mainly completed by highly educated people which may have excluded people without digital access.

This study is part of a larger project, in which similar data are collected with Latin American countries.

measures has impacted many aspects of people's lives. Lockdown involves staying home, decreasing mobility and separating people. ${ }^{1}$ Also, loss of income, loneliness, physical inactivity, limited access to basic services, increased access to online gambling and decreased family and social support. ${ }^{2}$ In previous epidemics, lockdown was associated with psychological effects, such as anxiety, depression and post-traumatic stress, which can be far-reaching and long-lasting. ${ }^{3}$ Additionally, measures such as social or physical distancing and uncertainty over disease status can affect mental health. ${ }^{4}$ These changes, which are related to sociostructural determinants, may not affect populations equally. ${ }^{5}$

Gender is one of the main social axes of inequities in health, particularly in mental health. ${ }^{67}$ Women tend to have higher lifetime prevalence of mood and anxiety disorders, while men have higher rates of substance use disorders and suicide mortality. ${ }^{7}$ Women are more exposed to gender-based violence which places them at increased risk of poorer 
mental health. ${ }^{7}$ In men, mental health problems are usually associated with rigidity in coping styles in order to respond to certain hegemonic male roles. ${ }^{78}$ Currently, evidence suggests that the COVID-19 pandemic has gendered effects, including differences in social and economic consequences. ${ }^{910}$

In China, women had significantly higher psychological distress than men during lockdown. ${ }^{11}$ Moreover, at the beginning of the pandemic in China, more acute posttraumatic symptoms and more sleep disturbance were observed in women. ${ }^{12}$ There were similar results in Italy with increased anxiety, depression and stress in women. ${ }^{13}$ A recent study in UK suggests that being young, a woman and living with children, especially preschool age children, have had a strong influence on mental distress increased under the conditions of the pandemic. ${ }^{14}$ Hence, evidence shows that there are gender differences in mental health before and during lockdown. However, to our knowledge, there is limited evidence on the gendered impact of lockdown on mental health. In fact, the public health measures applied for the control of COVID-19 transmission usually revolve around the biological and physical impact of the outbreak, with very little attention to mental health problems. ${ }^{15}$ Therefore, the main goal of our study is to assess the relations between social impact and mental health (anxiety and depression) among adults living in Spain during COVID-19 lockdown measures, taking a gender-based approach into account.

\section{METHODS}

We conducted a cross-sectional study among adults living in Spain during COVID-19 lockdown. Data were obtained through an online survey from 8 April to 28 May 2020. Study data were collected and managed using REDCap (Research Electronic Data Capture) electronic data capture tools hosted at Fundació Institut Universitari per a la recerca a l'Atenció Primària de Salut Jordi Gol i Gurina (IDIAPJGol). REDCap is a secure, web-based software platform designed to support data capture for research studies, providing (1) an intuitive interface for validated data capture; (2) audit trails for tracking data manipulation and export procedures; (3) automated export procedures for seamless data downloads to common statistical packages and (4) procedures for data integration and interoperability with external sources. ${ }^{1617}$

Recruitment was done through online platforms and social media using convenience and snowball sampling techniques. The questionnaire was written in Spanish and there were versions in English and French to achieve migrant populations. The questionnaire was created by a group of experts including psychologists, statisticians and epidemiologists. A pilot study was carried out and modifications were made to the questionnaire so that it was an easy-to-fill questionnaire. The inclusion criteria were to be 18 years or older and live in Spain during lockdown. Data collection was stopped when lockdown de-escalation started in all regions of Spain. Assuming alpha risk of $5 \%$, beta risk of $20 \%$ and OR of 1.3 , we consider that it was necessary to recruit a minimum of 1841 participants. PASS software was used for the sample size and power calculations (PASS 15 Power Analysis and Sample Size Software (2017), NCSS, Kaysville, Utah, USA, ncss.com/ software/pass).

Social impact was evaluated with the following variables: socioeconomic status, living conditions, COVID-19 experiences and health-oriented behaviour. Mental health was the main variable. Anxiety was measured by the Generalised Anxiety Disorder Scale (GAD-7), and was categorised as normal, mild, moderate and severe. Depression was assessed using Patient Health Questionnaire (PHQ-9) and was categorised in none-minimal, mild, moderate and moderately severe/severe. ${ }^{18}$ Anxiety was defined as persistent worry and anticipatory responses to future threats and depression as marked feelings of sadness, emptiness or irritability. ${ }^{19}$

Multivariate ordinal logistic regression models were constructed to evaluate the association between social impact variables, sociodemographic variables, anxiety and depression. Adjusted ordinal OR (aOR) and 95\% CI were calculated. The proportional odds assumption was evaluated using the likelihood ratio test. None of the fitted models violated such assumption. Analyses were stratified by sex, women and men. Respondents who had a non-binary sexual identity or did not identify with other categories were excluded from the analysis $(n=72)$. We evaluated effect modifications on a multiplicative scale by introducing interaction terms into the model and evaluating the $\mathrm{p}$ value for interaction with the likelihood ratio test. We evaluated the interaction term with the Bayesian Information Criteria. We made a causal diagram before the constructions of the models to minimise bias. To reduce misclassification bias that could arise from coding errors, the data manager checked and corrected impossible coding of categorical variables and unreliable outlier values for continuous variables. All analyses were performed in Stata 15.1.

\section{Patient and public involvement}

The research questions and aims of this study were driven by the researchers' lockdown experiences. Both the research team and participants contributed to the recruitment and dissemination of the on-line survey, using snowball strategies. The questionnaire was piloted with the target population.

\section{RESULTS}

A total of 7053 people were included in the analysis. Participant characteristics are available in table 1 . The mean age was $44.8 \pm 13.8$ years, women accounted for $71.1 \%$ of the sample and $71.3 \%$ have higher education. A total of $31.2 \%$ of women and $17.7 \%$ of men reported moderate and severe anxiety. A higher proportion of anxiety levels was found in the younger population (18-35 years), 39.7\% in women and $23.2 \%$ in men. Moderate and moderately 
Table 1 Sociodemographic characteristics, social impact variables and mental health scale of participants by sex in Spain during lockdown $(n=7053)$

\begin{tabular}{|c|c|c|c|c|}
\hline & $\begin{array}{l}\text { Women } \\
(n=5014)\end{array}$ & $\begin{array}{l}\text { Men } \\
(n=2039)\end{array}$ & $\begin{array}{l}\text { Total } \\
(\mathrm{n}=7053)\end{array}$ & P value* \\
\hline Age & & & & $<0.001$ \\
\hline$\geq 65$ years & $318(6.3 \%)$ & $247(12.1 \%)$ & $565(8.0 \%)$ & \\
\hline $35-64$ years & $3321(66.2 \%)$ & $1310(64.2 \%)$ & $4631(65.7 \%)$ & \\
\hline $18-35$ years & $1375(27.4 \%)$ & $482(23.6 \%)$ & $1857(26.3 \%)$ & \\
\hline Education & & & & 0.001 \\
\hline Primary education & 147 (2.9\%) & $84(4.1 \%)$ & $231(3.3 \%)$ & \\
\hline Secondary education & $1238(24.7 \%)$ & $557(27.3 \%)$ & $1795(25.5 \%)$ & \\
\hline Higher education & $3629(72.4 \%)$ & $1398(68.6 \%)$ & $5027(71.3 \%)$ & \\
\hline Country of birth & & & & 0.478 \\
\hline Spain & 4557 (90.9\%) & $1864(91.4 \%)$ & $6421(91.0 \%)$ & \\
\hline Other countries & $457(9.1 \%)$ & 175 (8.6\%) & $632(9.0 \%)$ & \\
\hline Living with $\leq 18$ years people & & & & $<0.001$ \\
\hline No & $3237(64.6 \%)$ & $1427(70.0 \%)$ & $4664(66.1 \%)$ & \\
\hline Yes & 1777 (35.4\%) & $612(30.0 \%)$ & 2389 (33.9\%) & \\
\hline Living with dependent people & & & & $<0.001$ \\
\hline No & $4264(85.0 \%)$ & $1800(88.3 \%)$ & $6064(86.0 \%)$ & \\
\hline Yes & $750(15.0 \%)$ & $239(11.7 \%)$ & $989(14.0 \%)$ & \\
\hline Adequate housing condition & & & & 0.050 \\
\hline Very much/considerably & $3550(70.8 \%)$ & $1397(68.5 \%)$ & $4947(70.1 \%)$ & \\
\hline Moderately & $956(19.1 \%)$ & $441(21.6 \%)$ & $1397(19.8 \%)$ & \\
\hline A bit/not at all & $508(10.1 \%)$ & $201(9.9 \%)$ & 709 (10.1\%) & \\
\hline COVID-19 diagnosis/symptomatology & & & & 0.033 \\
\hline No & $4072(81.2 \%)$ & $1700(83.4 \%)$ & $5772(81.8 \%)$ & \\
\hline Yes & $942(18.8 \%)$ & $339(16.6 \%)$ & $1281(18.2 \%)$ & \\
\hline Cohabitant with COVID-19 diagnosis/symptomatology & & & & 0.952 \\
\hline No & $4311(86.0 \%)$ & $1752(85.9 \%)$ & $6063(86.0 \%)$ & \\
\hline Yes & $703(14.0 \%)$ & $287(14.1 \%)$ & $990(14.0 \%)$ & \\
\hline Fear of COVID-19 infection & & & & $<0.001$ \\
\hline A bit/not at all & $1840(36.7 \%)$ & $855(41.9 \%)$ & $2695(38.2 \%)$ & \\
\hline Moderately & 1789 (35.7\%) & $734(36.0 \%)$ & $2523(35.8 \%)$ & \\
\hline Very much/considerably & $1385(27.6 \%)$ & $450(22.1 \%)$ & $1835(26.0 \%)$ & \\
\hline Death of loved ones & & & & 0.002 \\
\hline No & $4240(84.6 \%)$ & $1783(87.4 \%)$ & $6023(85.4 \%)$ & \\
\hline Yes & $774(15.4 \%)$ & $256(12.6 \%)$ & $1030(14.6 \%)$ & \\
\hline Essential work & & & & 0.010 \\
\hline No & $3696(73.7 \%)$ & $1563(76.7 \%)$ & $5259(74.6 \%)$ & \\
\hline Yes & $1318(26.3 \%)$ & $476(23.3 \%)$ & $1794(25.4 \%)$ & \\
\hline Employment condition & & & & 0.018 \\
\hline No change & $2883(57.5 \%)$ & $1169(57.3 \%)$ & $4052(57.5 \%)$ & \\
\hline Worsened & 2051 (40.9\%) & 817 (40.1\%) & $2868(40.7 \%)$ & \\
\hline Improved & $80(1.6 \%)$ & $53(2.6 \%)$ & $133(1.9 \%)$ & \\
\hline COVID-19 is a problem for your economy & & & & 0.939 \\
\hline Disagree & $450(9.0 \%)$ & $183(9.0 \%)$ & $633(9.0 \%)$ & \\
\hline
\end{tabular}

Continued 
Table 1 Continued

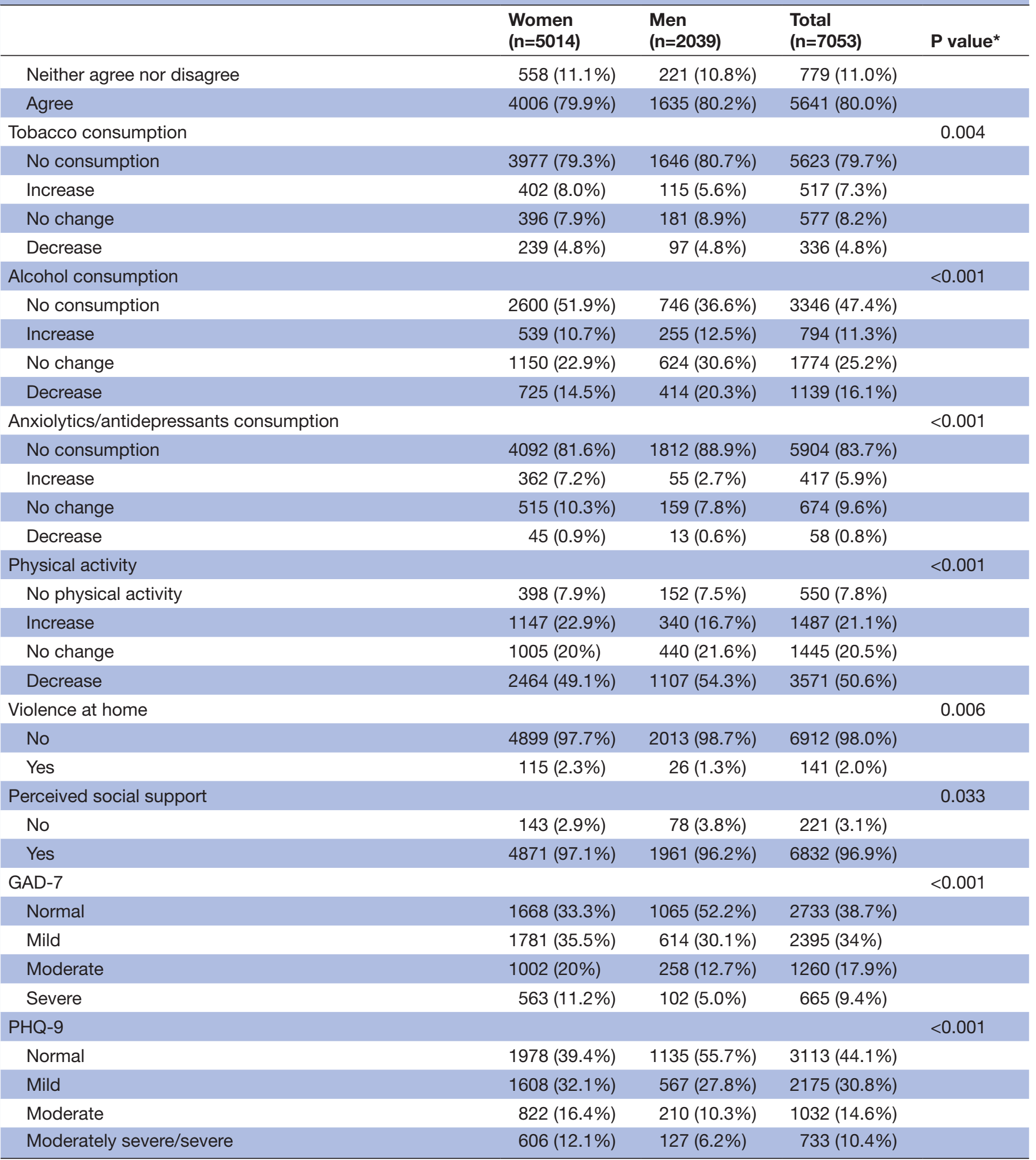

${ }^{*} \chi^{2} p$ value: differences between men and women.

GAD-7, Generalized Anxiety Disorder Scale; PHQ-9, Patient Health Questionnaire.

severe/severe depression levels were reported in $28.5 \%$ of women and $16.5 \%$ of men, being higher in the younger population (18-35 years), $42.1 \%$ in women and $28.4 \%$ in men.
No statistically significant interactions have been found. Tables 2 and 3 show different levels of anxiety and depression stratified by sex. In our study, perceiving inadequate housing conditions to cope with lockdown was associated 
Table 2 Association between sociodemographic characteristics, social impact and anxiety (GAD-7) ${ }^{\star}$ among women and men in Spain during lockdown $(n=7053)$

\begin{tabular}{|c|c|c|c|c|}
\hline & Women $(n=5014)$ & & Men ( $n=2039)$ & \\
\hline & aOR $^{1}(95 \% \mathrm{Cl})$ & $\mathbf{P}$ value† & aOR $(95 \% \mathrm{Cl})$ & P value \\
\hline Age & & & & \\
\hline$\geq 65$ years & 1.00 & $<0.001$ & 1.00 & $<0.001$ \\
\hline $35-64$ years & $1.48(1.17$ to 1.87$)$ & & 1.29 (0.94 to 1.76$)$ & \\
\hline $18-35$ years & 2.91 (2.26 to 3.74$)$ & & 2.06 (1.45 to 2.92$)$ & \\
\hline Education & & & & \\
\hline Primary education & 1.00 & 0.171 & 1.00 & 0.392 \\
\hline Secondary education & 0.79 (0.57 to 1.10$)$ & & 1.03 (0.65 to 1.64$)$ & \\
\hline Higher education & 0.75 (0.54 to 1.03$)$ & & $1.18(0.75$ to 1.84$)$ & \\
\hline Country of birth & & & & \\
\hline Spain & 1.00 & 0.746 & 1.00 & 0.620 \\
\hline Other countries & 0.97 (0.80 to 1.17$)$ & & $0.92(0.67$ to 1.26$)$ & \\
\hline Living with $\leq 18$ years people & 1.14 (1.01 to 1.28$)$ & 0.031 & 1.42 (1.16 to 1.73$)$ & 0.001 \\
\hline Living with dependent people & 1.06 (0.91 to 1.23$)$ & 0.484 & $1.30(0.99$ to 1.71$)$ & 0.058 \\
\hline Adequate housing condition & & & & \\
\hline Very much/considerably & 1.00 & $<0.001$ & 1.00 & $<0.001$ \\
\hline Moderately & 1.54 (1.35 to 1.77$)$ & & 1.70 (1.37 to 2.09$)$ & \\
\hline A bit/not at all & 2.14 (1.78 to 2.57$)$ & & 2.53 (1.89 to 3.38$)$ & \\
\hline COVID-19 diagnosis/symptomatology & 1.39 (1.20 to 1.61$)$ & $<0.001$ & 1.32 (1.02 to 1.70$)$ & 0.036 \\
\hline $\begin{array}{l}\text { Cohabitant with COVID-19 diagnosis/ } \\
\text { symptomatology }\end{array}$ & 1.26 (1.07 to 1.49$)$ & 0.006 & 1.06 (0.80 to 1.40$)$ & 0.678 \\
\hline Fear of COVID-19 infection & & & & \\
\hline A bit/not at all & 1.00 & $<0.001$ & 1.00 & $<0.001$ \\
\hline Moderately & $1.60(1.41$ to 1.81$)$ & & 1.82 (1.48 to 2.23$)$ & \\
\hline Very much/considerably & 4.23 (3.68 to 4.87$)$ & & 3.56 (2.82 to 4.51$)$ & \\
\hline Death of loved ones & 1.26 (1.09 to 1.45$)$ & 0.002 & 1.08 (0.83 to 1.40$)$ & 0.576 \\
\hline Essential work & 1.19 (1.05 to 1.34$)$ & 0.007 & $1.06(0.86$ to 1.31$)$ & 0.584 \\
\hline Employment condition & & & & \\
\hline No change & 1.00 & $<0.001$ & 1.00 & 0.013 \\
\hline Worsened & $1.42(1.27$ to 1.58$)$ & & $1.28(1.07$ to 1.54$)$ & \\
\hline Improved & $0.82(0.54$ to 1.27$)$ & & $0.75(0.42$ to 1.36$)$ & \\
\hline COVID-19 is a problem for your econor & & & & \\
\hline Disagree & 1.00 & 0.001 & 1.00 & 0.081 \\
\hline Neither agree nor disagree & 1.11 (0.88 to 1.41$)$ & & 0.89 (0.59 to 1.35$)$ & \\
\hline Agree & 1.37 (1.14 to 1.66$)$ & & 1.22 (0.88 to 1.68$)$ & \\
\hline Tobacco consumption & & & & \\
\hline No consumption & 1.00 & $<0.001$ & 1.00 & 0.001 \\
\hline Increase & 1.55 (1.28 to 1.89$)$ & & 1.98 (1.38 to 2.86$)$ & \\
\hline No change & 1.03 (0.85 to 1.25$)$ & & 1.35 (0.99 to 1.83$)$ & \\
\hline Decrease & 1.31 (1.01 to 1.68$)$ & & 1.05 (0.70 to 1.59$)$ & \\
\hline Alcohol consumption & & & & \\
\hline No consumption & 1.00 & 0.031 & 1.00 & 0.029 \\
\hline Increase & $1.17(0.98$ to 1.40$)$ & & 1.28 (0.96 to 1.70$)$ & \\
\hline No change & 0.88 (0.77 to 1.00$)$ & & 0.89 (0.72 to 1.11$)$ & \\
\hline
\end{tabular}

Continued 
Table 2 Continued

\begin{tabular}{|c|c|c|c|c|}
\hline & \multicolumn{2}{|l|}{ Women $(n=5014)$} & \multicolumn{2}{|l|}{ Men (n=2039) } \\
\hline & aOR $^{1}(95 \% \mathrm{Cl})$ & P value & aOR $(95 \% \mathrm{Cl})$ & $\mathbf{P}$ value $†$ \\
\hline Decrease & $0.96(0.81$ to 1.13$)$ & & 1.22 (0.95 to 1.56$)$ & \\
\hline No consumption & 1.00 & $<0.001$ & 1.00 & $<0.001$ \\
\hline Increase & 6.05 (4.91 to 7.46$)$ & & $6.91(4.13$ to 11.58$)$ & \\
\hline Decrease & 1.23 (0.71 to 2.12$)$ & & $1.81(0.57$ to 5.68$)$ & \\
\hline \multicolumn{5}{|l|}{ Physical activity } \\
\hline No physical activity & 1.00 & $<0.001$ & 1.00 & 0.230 \\
\hline Increase & 0.72 (0.58 to 0.90$)$ & & $0.81(0.55$ to 1.19$)$ & \\
\hline Perceived social support & 0.58 (0.43 to 0.79$)$ & 0.001 & 0.88 (0.55 to 1.43$)$ & 0.607 \\
\hline
\end{tabular}

*GAD-7 was categorised in normal, mild, moderate and severe.

†P value: statistical significance is Wald test.

aOR, adjusted ordinal OR; GAD-7, Generalized Anxiety Disorder Scale.

with higher anxiety (aOR(women): $2.1495 \% \mathrm{CI} 1.78$ to 2.57, aOR(men): $2.53,95 \%$ CI 1.89 to 3.38$)$ and depression level (aOR(women): $2.1395 \%$ CI 1.78 to 2.55 , aOR(men): $2.27,95 \%$ CI 1.69 to 3.05 ), especially in men. In addition, men appeared to be more anxious when living with children under 18 years during lockdown (aOR: $1.42,95 \%$ CI 1.16 to 1.73 ), compared with women (aOR: 1.14, 95\% CI 1.01 to 1.28). Living with children was a protective factor for depression among women (aOR: $0.87,95 \%$ CI 0.77 to 0.98 ).

Having COVID-19 diagnosis, or compatible symptomatology, was related to greater anxiety levels in women (aOR: $1.39,95 \%$ CI 1.20 to 1.61 ). Living with someone with a diagnosis or suspected COVID-19 was also associated with anxiety in women (aOR: $1.26,95 \%$ CI 1.07 to 1.49 ) but not with depression, neither in women nor in men. Besides, women had increased anxiety (aOR: 1.26, 95\% CI 1.09 to 1.45 ) and depression (aOR: $1.22,95 \%$ CI 1.06 to 1.42 ) levels when facing the death of loved ones. Fear of COVID-19 infection was associated with higher anxiety levels, especially in women (aOR: 4.23 , 95\% CI 3.68 to 4.87 ).

In women, there was a positive association between engaging in essential work (eg, health professionals) and anxiety levels (aOR: $1.19,95 \%$ CI 1.05 to 1.34 ), while in men, a protective association was found for depression (aOR: $0.69,95 \%$ CI 0.55 to 0.86 ). There was an increase in anxiety levels among women when employment conditions worsened during lockdown (aOR: 1.42, 95\% CI 1.27 to 1.58 ). In men, worsening working conditions were associated with higher levels of depression (aOR: 1.57, $95 \%$ CI 1.30 to 1.89 ). In women, perceiving COVID-19 as a problem for their economy was associated with higher levels of anxiety (aOR: $1.37,95 \%$ CI 1.14 to 1.66 ) and depression (aOR: $1.51,95 \%$ CI 1.24 to 1.84 ).

In relation to changes in health-oriented behaviour, increased anxiolytics consumption during lockdown was associated with greater anxiety $(\mathrm{aOR}$ (women): 6.05, 95\% CI 4.91 to $7.46, \mathrm{aOR}(\mathrm{men}): 6.91,95 \% \mathrm{CI} 4.13$ to 11.58 ) and depression (aOR(women): $4.65,95 \%$ CI 3.78 to 5.72 , aOR(men): $6.03,95 \%$ CI 3.60 to 10.10 ) levels. On the other hand, increased physical activity was a protective factor for depression, especially among men (aOR(women): $0.5095 \% \mathrm{CI} 0.40$ to 0.62 , aOR(men): 0.35 $95 \%$ CI 0.24 to 0.52 ).

Women who experienced gender-based violence $(2.3 \%)$ reported greater anxiety (aOR: $1.68,95 \%$ CI 1.18 to 2.39) and depression levels (aOR: 1.97, 95\% CI 1.37 to 2.84$)$. Violence in men (1.3\%) was not associated with poorer mental health. Finally, social support (either from neighbours, family or friends) was a protective factor against suffering from anxiety (aOR: $0.58,95 \%$ CI 0.43 to 0.79 ) and depression (aOR: $0.36,95 \%$ CI 0.26 to 0.49 ) only among women.

\section{DISCUSSION}

Our findings suggest that there is a relation between social impact and mental health during COVID-19 lockdown according to gender, age and socioeconomic conditions. Globally, approximately one-third of women experienced anxiety and depression, while in men, these symptoms accounted for about $17 \%$. These results considerably differ from the Spanish National Health Survey (2017), in which $9.1 \%$ of women and $4.3 \%$ of men reported chronic anxiety. ${ }^{20}$ We observe that the impact of lockdown on the 
Table 3 Association between sociodemographic characteristics, social impact and depression $(\mathrm{PHQ}-9)^{\star}$ among women and men in Spain during lockdown $(n=7053)$

\begin{tabular}{|c|c|c|c|c|}
\hline & \multicolumn{2}{|l|}{ Women $(n=5014)$} & \multicolumn{2}{|l|}{ Men (n=2039) } \\
\hline & aOR $^{1}(95 \% \mathrm{Cl})$ & $P$ value $†$ & aOR $(95 \% \mathrm{Cl})$ & $P$ value \\
\hline \multicolumn{5}{|l|}{ Age } \\
\hline$\geq 65$ years & 1.00 & $<0.001$ & 1.00 & $<0.001$ \\
\hline $35-64$ years & 2.07 (1.59 to 2.63$)$ & & 1.93 (1.37 to 2.72$)$ & \\
\hline $18-35$ years & 5.02 (3.84 to 6.57$)$ & & 4.46 (3.07 to 6.47$)$ & \\
\hline \multicolumn{5}{|l|}{ Education } \\
\hline Primary education & 1.00 & 0.437 & 1.00 & 0.024 \\
\hline Secondary education & 1.07 (0.76 to 1.53$)$ & & 1.69 (1.01 to 2.82$)$ & \\
\hline Higher education & 0.98 (0.70 to 1.37$)$ & & $1.92(1.16$ to 3.17$)$ & \\
\hline \multicolumn{5}{|l|}{ Country of birth } \\
\hline Spain & 1.00 & 0.557 & 1.00 & 0.499 \\
\hline Other countries & 1.06 (0.88 to 1.28$)$ & & 1.11 (0.81 to 1.51$)$ & \\
\hline Living with $\leq 18$ years people & 0.87 (0.77 to 0.98$)$ & 0.023 & 0.83 (0.67 to 1.03$)$ & 0.824 \\
\hline Living with dependent people & 0.94 (0.80 to 1.09$)$ & 0.411 & 1.29 (0.97 to 1.73$)$ & 0.079 \\
\hline \multicolumn{5}{|l|}{ Adequate housing condition } \\
\hline Very much/considerably & 1.00 & $<0.001$ & 1.00 & $<0.001$ \\
\hline Moderately & 1.53 (1.34 to 1.76$)$ & & $1.52(1.23$ to 1.89$)$ & \\
\hline A bit/not at all & 2.13 (1.78 to 2.55$)$ & & 2.27 (1.69 to 3.05$)$ & \\
\hline COVID-19 diagnosis/symptomatology & 1.65 (1.43 to 1.92$)$ & $<0.001$ & 1.90 (1.47 to 2.46$)$ & $<0.001$ \\
\hline Cohabitant with COVID-19 diagnosis/symptomatology & $1.02(0.86$ to 1.21$)$ & 0.803 & 0.74 (0.56 to 0.99$)$ & 0.042 \\
\hline \multicolumn{5}{|l|}{ Fear of COVID-19 infection } \\
\hline A bit/not at all & 1.00 & $<0.001$ & 1.00 & $<0.001$ \\
\hline Moderately & 1.14 (0.99 to 1.29$)$ & & $1.22(0.99$ to 1.51$)$ & \\
\hline Very much/considerably & 1.91 (1.67 to 2.19$)$ & & 1.92 (1.51 to 2.43$)$ & \\
\hline Death of loved ones & $1.22(1.06$ to 1.42$)$ & 0.006 & 1.21 (0.93 to 1.57$)$ & 0.152 \\
\hline Essential work & 0.93 (0.82 to 1.05$)$ & 0.257 & 0.69 (0.55 to 0.86$)$ & 0.001 \\
\hline \multicolumn{5}{|l|}{ Employment condition } \\
\hline No change & 1.00 & $<0.001$ & 1.00 & $<0.001$ \\
\hline Worsened & 1.36 (1.22 to 1.52$)$ & & 1.57 (1.30 to 1.89$)$ & \\
\hline Improved & $0.62(0.40$ to 0.96$)$ & & 0.97 (0.54 to 1.73$)$ & \\
\hline \multicolumn{5}{|l|}{ COVID-19 is a problem for your economy } \\
\hline Disagree & 1.00 & $<0.001$ & 1.00 & 0.188 \\
\hline Neither agree nor disagree & 1.09 (0.85 to 1.39$)$ & & 1.12 (0.73 to 1.72$)$ & \\
\hline Agree & 1.51 (1.24 to 1.84$)$ & & $1.32(0.94$ to 1.85$)$ & \\
\hline \multicolumn{5}{|l|}{ Tobacco consumption } \\
\hline No consumption & 1.00 & $<0.001$ & 1.00 & 0.002 \\
\hline Increase & 1.85 (1.52 to 2.26$)$ & & 2.04 (1.41 to 2.95$)$ & \\
\hline No change & 1.19 (0.98 to 1.46$)$ & & 1.11 (0.81 to 1.52$)$ & \\
\hline Decrease & $1.23(0.95$ to 1.58$)$ & & $0.98(0.65$ to 1.50$)$ & \\
\hline \multicolumn{5}{|l|}{ Alcohol consumption } \\
\hline No consumption & 1.00 & $<0.001$ & 1.00 & 0.001 \\
\hline Increase & $1.36(1.14$ to 1.63$)$ & & $1.30(0.98$ to 1.74$)$ & \\
\hline No change & $0.86(0.75$ to 0.98$)$ & & 0.73 (0.58 to 0.92$)$ & \\
\hline Decrease & 1.06 (0.90 to 1.25$)$ & & 1.05 (0.82 to 1.35$)$ & \\
\hline
\end{tabular}


Table 3 Continued

\begin{tabular}{|c|c|c|c|c|}
\hline & \multicolumn{2}{|l|}{ Women $(n=5014)$} & \multicolumn{2}{|l|}{ Men $(n=2039)$} \\
\hline & aOR $^{1}(95 \% \mathrm{Cl})$ & $P$ value & aOR $(95 \% \mathrm{Cl})$ & $\mathbf{P}$ value† \\
\hline \multicolumn{5}{|c|}{ Anxiolytics/antidepressants consumption } \\
\hline No consumption & 1.00 & $<0.001$ & 1.00 & $<0.001$ \\
\hline Increase & 4.65 (3.78 to 5.72$)$ & & 6.03 (3.60 to 10.10$)$ & \\
\hline No change & 2.67 (2.24 to 3.20$)$ & & 1.94 (1.41 to 2.69$)$ & \\
\hline Decrease & 1.16 (0.66 to 2.03 ) & & 2.27 (0.78 to 6.60$)$ & \\
\hline \multicolumn{5}{|l|}{ Physical activity } \\
\hline No physical activity & 1.00 & $<0.001$ & 1.00 & $<0.001$ \\
\hline Increase & 0.50 (0.40 to 0.62$)$ & & 0.35 (0.24 to 0.52$)$ & \\
\hline No change & $0.54(0.43$ to 0.68$)$ & & $0.48(0.33$ to 0.69$)$ & \\
\hline Decrease & 0.85 (0.69 to 1.04$)$ & & 0.62 (0.44 to 0.86$)$ & \\
\hline Violence at home & 1.97 (1.37 to 2.84$)$ & $<0.001$ & 1.66 (0.80 to 3.43$)$ & 0.175 \\
\hline Perceived social support & 0.36 (0.26 to 0.49$)$ & 0.000 & 0.74 (0.47 to 1.18$)$ & 0.204 \\
\hline
\end{tabular}

${ }^{*} \mathrm{PHQ}-9$ was categorised in none-minimal, mild, moderate and moderately severe/severe. †P value: statistical significance derived from Wald test. aOR, adjusted ordinal OR; PHQ-9, Patient Health Questionnaire.

young population (18-35 years), and especially among women, has been worse than on the older population. An explanation could be that lockdown measures have meant a more radical change in young people's day-to-day activities, compared with older people. However, previous evidence has highlighted that lockdown measures have shown that older adults are highly susceptible to social isolation which has mental health consequences. ${ }^{21}$

Furthermore, poorer mental health was associated with perceived inadequate housing conditions during lockdown, especially in men. Feeling unsatisfied with one's housing could result in psychological distress and mental health problems. This dimension includes overcrowding, housing insecurity and physical housing conditions. ${ }^{22}$ Adequate housing should provide security, protection from domestic injuries and an acceptable indoor temperature. ${ }^{22}$ Therefore, our finding may be related to people living in worse housing conditions and having low income and/or poor labour conditions. In addition, the evidence in Barcelona city (Spain) shows that the incidence rates of COVID-19 followed a socioeconomic gradient, ${ }^{23}$ in which housing conditions play a key role in quarantine compliance. These factors could explain that poor mental health during lockdown is related to sociostructural determinants affecting more vulnerable population.

In this regard, women's mental health seemed to be more affected when economic conditions worsened during the pandemic. Also, women reported greater concern for their personal finances. This suggests that women's economy may have been more adversely affected during the pandemic, as they are more involved in temporary, part-time and precarious employment than men. ${ }^{24}$ This is related that women are more dedicated to caring tasks, which leads them to look for jobs that allow for an acceptable work-life balance. However, men whose economic situation worsened during the pandemic were more likely to report depression. Social pressures on men to gain and provide financial resources, and the uncertainty of their economic future could explain these results. ${ }^{25}$ It is important that, as in other Southern European countries, Spain's limited unemployment protection could have impact on the population's mental health. ${ }^{25}$

Our findings indicate that women with anxiety have more fear of COVID-19 infection. Similar results have been shown in other studies. ${ }^{3}$ Women may fear, either having to care for people with a COVID-19 diagnosis/ symptomatology, or being limited to care for others if contracting COVID-19 themselves. On other hand, the higher association of anxiety in men living with children and/or adolescents may be due to men being less used to taking care and spending time with them while women regularly balance part-time work and family responsibilities. ${ }^{7}$

The proportion of women who reported gender-based violence during lockdown was low (2.3\%) compared with a survey conducted in Spain (2015), in which $15.5 \%$ of women reported to have suffered violence. ${ }^{26}$ However, there was an increase in the number of calls for genderbased violence offered by support services during lockdown. ${ }^{27}$ This raises the need to identify and favour channels of help to women who are living with their aggressor.

This study has limitations. The survey was only available online and was mainly completed by highly educated people and it may have excluded people without digital access. Non-representative responses are a handicap of online surveys, since they do not capture the responses of 
those who lack access and/or skills in using the internet (eg, the elderly, those with lower education or those who reside in remote locations).$^{28}$ In addition, we had more responses from women than men. This requires planning strategies to ensure that there is greater participation by men. However, as the analyses were stratified by sex, the main results can be compared with their reference group. On the other hand, we do not know the proportion of people from our sample who had a mental health diagnosis before lockdown. However, the results show important changes in the mental health of Spanish residents compared with previous years. Also, we will carry out a qualitative study and in 6 months a cross-sectional study. We will also carry out this same study in several Latin American countries in order to compare the results in different population.

In conclusion, these findings suggest that the social impact of lockdown and its consequences appear to be worse in women and young people. Poorer mental health was mainly related to fear of COVID-19 infection, worsened economy and perceived inadequate housing conditions to cope with lockdown. Although these findings could be generalised to other contexts, further in-depth analysis should be conducted to ensure a sociocultural perspective considering the socioeconomic reality and management of the pandemic in other countries. Intervention strategies and policies for public health emergencies should include mental health and its determinants, taking a gender-based approach into account, in order to reduce health inequities.

\section{Author affiliations}

${ }^{1}$ Fundació Institut Universitari per a la recerca a l'Atenció Primària de Salut Jordi Gol i Gurina (IDIAPJGol), Barcelona, Spain

${ }^{2}$ ISGlobal, Barcelona, Spain

${ }^{3}$ Spanish Consortium for Research on Epidemiology and Public Health (CIBERESP), Spain, Spain

${ }^{4}$ Universitat Pompeu Fabra, Barcelona, Spain

${ }^{5}$ Unitat de Suport a la Recerca Terres de l'Ebre, Fundació Institut Universitari per a la recerca a l'Atenció Primària de Salut Jordi Gol i Gurina (IDIAPJGol), Tortosa, Catalunya, Spain

${ }^{6}$ Unitat Docent de Medicina de Família i Comunitària Tortosa-Terres de L'Ebre, Institut Català de la Salut, Tortosa, Catalunya, Spain

${ }^{7}$ Departament d'Infermeria, Universitat de Girona. Emili Grahit, 77, Girona, Spain

Twitter Constanza Jacques-Aviñó @cjacques18, Laura Medina-Perucha @ Lauramedp, Talita Duarte-Salles @TDuarte_Salles and Anna Berenguera @ ABerenguera

Acknowledgements The authors gratefully acknowledge Ramon Monfà for assistance in data entry and Patryck Bialoskorski for his contributions revising the language. We also thank all the people who have participated in completing the survey.

Contributors CJA, TLJ, LMP, JdB and AB conceived the study idea. All authors (CJA, TLJ, LMP, JdB, AQG, TDS and AB) contributed to study design and data collection. TLJ performed the statistical analysis. CJA drafted the initial version of the manuscript. All authors (CJA, TLJ, LM-P, JdB, AQG, TDS and AB) interpreted the results, critically reviewed the manuscript and approved the final version for submission.

Funding This work was supported by Spain's Ministry of Science and Innovation through the Carlos III Health Institute and European Union ERDF funds (European Regional Development Fund) through the Research Network in Preventive Activities and Health Promotion in Primary Care (redlAPP, RD16/0007/0001).
Competing interests None declared.

Patient and public involvement Patients and/or the public were involved in the design, or conduct, or reporting, or dissemination plans of this research. Refer to the Methods section for further details.

Patient consent for publication Not required.

Ethics approval We have obtained the necessary ethical approvals prior to the start of the research from our organisation (IDIAPJGoL) (20/063-PCV).

Provenance and peer review Not commissioned; externally peer reviewed.

Data availability statement Data are available on reasonable request. All data relevant to the study are included in the article.

Open access This is an open access article distributed in accordance with the Creative Commons Attribution Non Commercial (CC BY-NC 4.0) license, which permits others to distribute, remix, adapt, build upon this work non-commercially, and license their derivative works on different terms, provided the original work is properly cited, appropriate credit is given, any changes made indicated, and the use is non-commercial. See: http://creativecommons.org/licenses/by-nc/4.0/.

\section{ORCID iDs}

Constanza Jacques-Aviñó http://orcid.org/0000-0001-8506-780X

Laura Medina-Perucha http://orcid.org/0000-0002-2981-2614

Talita Duarte-Salles http://orcid.org/0000-0002-8274-0357

Anna Berenguera http://orcid.org/0000-0002-0889-2002

\section{REFERENCES}

1 Centers for Disease Control and Prevention. Quarantine and isolation. centers for disease control and prevention, 2017. Available: https://www.cdc.gov/quarantine/index.html

2 Moreno C, Wykes T, Galderisi S, et al. How mental health care should change as a consequence of the COVID-19 pandemic. Lancet Psychiatry 2020;7:813-24.

3 Brooks SK, Webster RK, Smith LE, et al. The psychological impact of quarantine and how to reduce it: rapid review of the evidence. The Lancet 2020;395:912-20.

4 Holmes EA, O'Connor RC, Perry VH, et al. Multidisciplinary research priorities for the COVID-19 pandemic: a call for action for mental health science. Lancet Psychiatry 2020;7:547-60.

5 Marmot M, justice S. Social justice, epidemiology and health inequalities. Eur J Epidemiol 2017;32:537-46.

6 The Lancet. The gendered dimensions of COVID-19. Lancet 2020;395:1168.

7 Kiely KM, Brady B, Byles J. Gender, mental health and ageing. Maturitas 2019;129:76-84.

8 Jacques-Aviñó C, García de Olalla P, González Antelo A, et al. The theory of masculinity in studies on HIV. A systematic review. Glob Public Health 2019;14:601-20.

9 Gebhard C, Regitz-Zagrosek V, Neuhauser HK, et al. Impact of sex and gender on COVID-19 outcomes in Europe. Biol Sex Differ 2020;11:1-13.

10 Castellanos-Torres E, Mateos JT, Chilet-Rosell E. COVID-19 en clave de género. Gac Sanit 2020;1:1-11.

11 Qiu J, Shen B, Zhao M, et al. A nationwide survey of psychological distress among Chinese people in the COVID-19 epidemic: implications and policy recommendations. Gen Psychiatr 2020;33:e100213:1-4.

12 Liu N, Zhang F, Wei C, et al. Prevalence and predictors of PTSS during COVID-19 outbreak in China hardest-hit areas: gender differences matter. Psychiatry Res 2020;287:19-21.

13 Mazza C, Ricci E, Biondi S, et al. A nationwide survey of psychological distress among Italian people during the COVID-19 pandemic: immediate psychological responses and associated factors. Int J Environ Res Public Health 2020;17:3165:1-14.

14 Pierce M, Hope $\mathrm{H}$, Ford T, et al. Mental health before and during the COVID-19 pandemic: a longitudinal probability sample survey of the UK population. Lancet Psychiatry 2020;7:1-10.

15 Ho CS, Chee CY, Ho RC. Mental health strategies to combat the psychological impact of COVID-19 beyond paranoia and panic. Ann Acad Med Singap 2020;49:1-3.

16 Harris PA, Taylor R, Thielke R, et al. Research electronic data capture (REDCap)--a metadata-driven methodology and workflow process for providing translational research informatics support. J Biomed Inform 2009;42:377-81.

17 Harris PA, Taylor R, Minor BL, et al. The REDCap Consortium: building an international community of software platform partners. $J$ Biomed Inform 2019;95:103208. 
18 Score T. Primary care evaluation of mental disorders patient health questionnaire (PRIME-MD PHQ, 1999: 7-9.

19 American Psychiatric Association. American psychiatric association: diagnostic and statistical manual of mental disorders. 5th ed. Arlington, 2013.

20 Ministerio de Salud de España. Encuesta Nacional de Salud España 2017. Informe monográfico de Salud mental. Encuesta Nacional de Salud ENSE, España 2017, 2017.

21 Bavel JJV, Baicker K, Boggio PS, et al. Using social and behavioural science to support COVID-19 pandemic response. Nat Hum Behav 2020;4:460-71.

22 Marí-Dell'Olmo M, Novoa AM, Camprubí L, et al. Housing policies and health inequalities. Int $J$ Health Serv 2017;47:207-32.

23 Baena-Díez JM, Barroso M, Cordeiro-Coelho SI, et al. Impact of COVID-19 outbreak by income: hitting hardest the most deprived. $J$ Public Health 2020:1-6.
24 European Institute for Gender Equality. Economic hardship and gender, 2020: 25-7. https://eige.europa.eu/covid-19-and-genderequality/economic-hardship-and-gender

25 Cortès-Franch I, Escribà-Agüir V, Benach J, et al. Employment stability and mental health in Spain: towards understanding the influence of gender and partner/marital status. BMC Public Health 2018;18:1-11.

26 Delegación del Gobierno para la Violencia de Género. Macroencuesta de Violencia contra la Mujer 2015. Avance de resultados Delegación del Gobierno para la Violencia de Género [Internet]. Boletín Oficial del Estado, 2015. Available: http://www.publ icacionesoficiales.boe.es

27 Secretaria de Estado de Igualdad y contra la Violencia de Género. Principales datos sobre Violencia de Género. Julio 2020. Delegación del Gobierno Contra La Violencia de Género, 2020.

28 Ball HL. Conducting online surveys. J Hum Lact 2019;35:413-7. 